\title{
Effect of angiotensin II blockade on central blood pressure and arterial stiffness in subjects with hypertension
}

This article was published in the following Dove Press journal: International Journal of Nephrology and Renovascular Disease 2 December 2010

Number of times this article has been viewed

\author{
Michel E Safar \\ Université Paris Descartes, \\ Assistance Publique-Hôpitaux \\ de Paris, Hôtel-Dieu Centre de \\ Diagnostic et de Thérapeutique, \\ Paris, France
}

Correspondence: Michel Safar

Diagnosis Center, Hôpital Hôtel-

Dieu, I place du Parvis Notre-Dame,

75I8I Paris Cedex 04, France

$\mathrm{Tel}+33$ । 42348025

Fax +33 I 42348632

Email michel.safar@htd.aphp.fr

\begin{abstract}
In hypertension, the blood pressure curve may be divided into two sets of components. The first set is mean arterial pressure, steady flow, and vascular resistance, thus acting on small arteries; the second set refers to large arteries, hence to pulse pressure, arterial stiffness, and wave reflections. The angiotensin-converting enzyme (ACE) inhibitor perindopril not only reduces mean arterial pressure but also acts specifically on pulse pressure. The effect on pulse pressure predominates on central rather than peripheral (brachial) large arteries, reducing aortic stiffness and most wave reflections. Such hemodynamic changes are not observed with standard $\beta$-blockade, which reduces aortic stiffness and brachial systolic and pulse pressure but not central pulse pressure and wave reflections. In hypertensive subjects, perindopril and other ACE inhibitors seem to predict more consistently the reduction of cardiovascular events, mainly of cardiac origin, than standard $\beta$-blockers alone. This effect is associated with the important biochemical finding that mechanotransductions of angiotensin and $\beta$-blockade are markedly different, acting in the former specifically on the $\alpha 5 \beta 1$ integrin complex and on the fibronectin ligand of arterial vessels.
\end{abstract}

Keywords: antihypertensive therapy, arterial stiffness, renal function

\section{Introduction}

Because they are the simple consequence of the well established auscultatory method, blood pressure (BP) measurements are usually obtained from the definition of only two specific points of the BP curve, ie, peak systolic BP and end diastolic BP. After the advent of antihypertensive therapy and following the results of therapeutic trials in populations of subjects with hypertension, it was proposed that cardiovascular effectiveness could be better evaluated from systolic BP than from diastolic BP. However, these standard definitions are oversimplified and now require substantial revision.

Blood pressure is the force applied per unit area on a given vessel, which determines the flow of blood. Pressure and flow result from the properties of the heart as a pump and the characteristics of the arterial system. However, pressure and flow vary during the cardiac cycle and are therefore called pulsatile pressure and flow. When the BP curve is submitted to Fourier analysis and written as a series of sine waves, these waves are called oscillatory pressure and flow. The zero term equals the mean value (mean arterial pressure) of BP, and the harmonics are the oscillatory terms, summarized by pulse pressure (pulse pressure = systolic BP - diastolic BP, see Figure 1).

After World War II, a group of cardiovascular physiologists suggested that the pulsatile BP curve could be better described when divided into two components, ie, a steady 


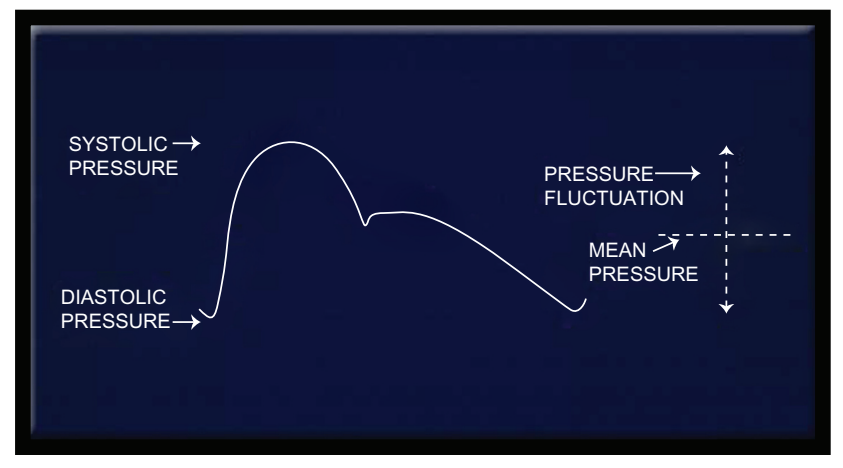

Figure I The different components of the pulsatile blood pressure curve. ${ }^{1-3}$ For mean arterial pressure, the area under the mean arterial pressure curve is exactly equal to the area under the pulsatile blood pressure curve, which means that the two curves are able to produce exactly the same cardiac work. ${ }^{1-3}$

component (mean arterial pressure) and a pulsatile component (pulse pressure), as shown in Figure 1. This review focuses on, firstly, the description of the hemodynamics of untreated hypertension according to the basic principles defined from mean arterial pressure and pulse pressure, and, secondly, application of these principles to the study of angiotensin blockade. Perindopril was the first angiotensin-converting enzyme (ACE) inhibitor to be studied in subjects with hypertension using mean arterial pressure and pulse pressure. The role of the other ACE inhibitors in the mechanisms of angiotensin blockade is indicated in the Appendix.

\section{Systemic hemodynamics in untreated hypertension}

Large arteries have two distinct functions. ${ }^{1-4}$ The first consists of transporting blood from the heart toward peripheral tissues in order to satisfy their metabolic needs. This function requires the presence of a steady pressure gradient, represented principally by mean arterial pressure. In order to define this gradient, mean arterial pressure, calculated from the cross-sectional area under the BP curve divided by cardiac cycle time, is subtracted from central venous pressure, which is normally close to zero. The second function of large arteries consists of instantaneously accommodating the volume of blood ejected from the left ventricle of the heart, storing part of the stroke volume during systolic ejection, and carrying this volume during diastole, thereby ensuring continuous perfusion of organs and tissues at the peripheral level. This specific function of arteries is usually described in terms of elasticity or stiffness of the aorta or an individual artery and is usually associated with the generation of wave reflections.

Large artery elasticity or stiffness is usually determined from systolic and diastolic changes in artery diameter, coupled with measurement of local pulse pressure, which is the difference between systolic BP and diastolic BP. ${ }^{1-4}$ However, the most common method for evaluating arterial stiffness is based on the study of pulse wave velocity, ie, the velocity of the BP propagation wave along a given conduit artery, eg, the aorta. Pulse wave velocity can be determined from measurements of pulse transit time and the distance travelled by the pulse between the common carotid and femoral arteries. Aortic pulse wave velocity (carotid to femoral) can be measured by applanation tonometry, mechanotransducer, or Doppler probes and is regarded as the gold standard for determining arterial stiffness, independent of wave activity. The technique of applanation tonometry is widely used to evaluate central $\mathrm{BP}$ and also wave reflections through the determination of the augmentation index, a noninvasive parameter (Figure 2). The augmentation index is a measure of the contribution that wave reflection makes to the central pressure wave. It is defined as the difference between the second and first peaks (P2-P1) corresponding to systolic BP and is expressed as a percentage of the pulse pressure. Therefore, the augmentation index is a quite indirect measure of systemic stiffness and is mostly a direct measure of wave reflection, a parameter defined later in this review.

It is widely accepted nowadays ${ }^{1}$ that the aortic BP curve represents the mathematical summation of an incident pressure wave, coming from the heart through ventricular ejection, and a reflected wave depending on a given arterial or arteriolar site characterized by three independent parameters, ie, the value of reflection coefficients, the degree of arterial stiffening, and the distance between the heart and the site of reflecting points (Figure 3). Under normal conditions, the complex interaction between these parameters is responsible for the physiologic amplification of the pressure pulse observed between central and peripheral arteries, whereas mean arterial pressure remains almost constant along the arterial tree. Under pathologic conditions, as frequently observed in elderly people, particularly those with hypertension, both increased arterial stiffening and reflection sites closer to the heart (ie, reflection sites at the level of arteriolar or arterial bifurcations) cause the backward pressure wave to return sooner (ie, during the systolic component of the aortic BP curve), resulting in a greater summation between the forward and backward waves and consequently a higher aortic pulse pressure and systolic peak. ${ }^{2,3}$ In older subjects with hypertension, such changes are responsible for a peculiar hemodynamic pattern involving a disproportionate increase of systolic BP over diastolic BP, with potentially a loss in pulse pressure amplification.

Finally, in the past, hypertension was simply defined from high mean arterial pressure, associated with elevated systolic 

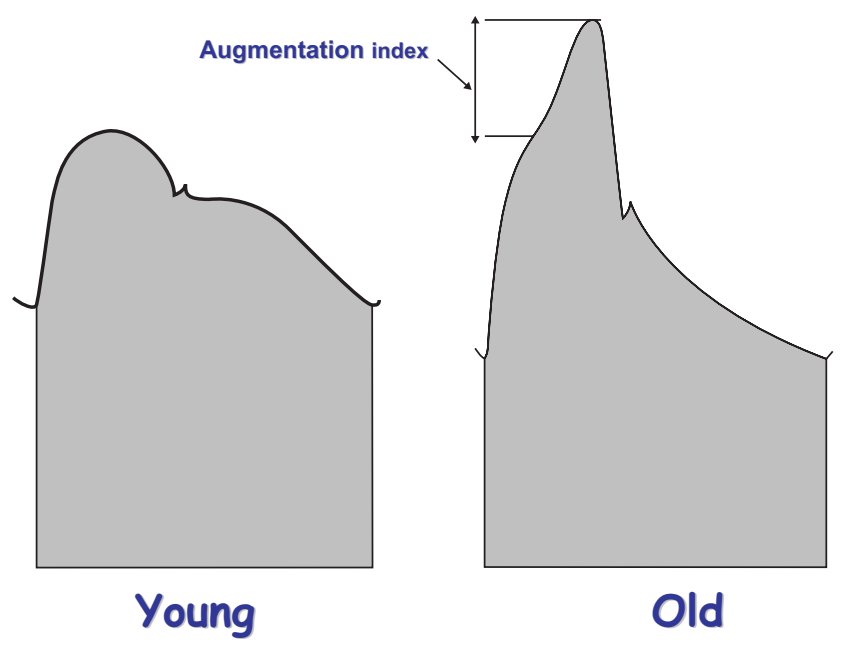

Figure 2 The augmentation index is the ratio of the difference between peak systolic blood pressure, shoulder of the ascending part of the blood pressure curve, and pulse pressure. ${ }^{1-4}$ The augmentation index, measured as a percentage, represents the supplementary increase in systolic blood pressure due to wave reflections. This hemodynamic profile is observed in the elderly but not in young people (see also Figure 3).

BP and diastolic BP. Mean arterial pressure divided by cardiac output enables calculation of vascular resistance, considered to be an index of the caliber of small arteries. Increased vascular resistance some decades ago was considered to be the unique and universal hallmark of hypertension. Nowadays, the buffering function of large arteries is also taken into consideration. This changing definition is due to the high frequency of systolic hypertension in the elderly, which generates mainly increased arterial stiffness and disturbed wave reflections but not necessarily increased vascular resistance.

\section{Hemodynamic effects of angiotensin II inhibition in hypertension}

The point to consider here is that the ACE inhibitor perindopril is able not only to decrease mean arterial pressure but also, through its effect on conduit arteries, to decrease brachial pulse pressure ${ }^{5-7}$ and, even more selectively, central (carotid and aortic) pulse pressure (see Table 1).

We and others have shown in many previous clinical studies that ACE inhibitors may increase arterial diameter and decrease arterial stiffness independently of changes in mean arterial pressure. ${ }^{8,9}$ In addition, ACE inhibitors have been shown to act selectively on the backward aortic pressure wave, causing the reflected wave to return during the diastolic (but not the systolic) component of the BP curve, thus reducing aortic pulse pressure and systolic peak much more than brachial pulse and systolic BP. Thus, the decrease in arterial stiffness and change in the pattern of pulse wave reflections observed with perindopril contribute significantly to a decrease in BP through arterial (and not exclusively arteriolar) effects. Both in animals and in humans, there is strong evidence to support this assumption, particularly following long-term treatment with ACE inhibition. Firstly, in spontaneously hypertensive rats and in patients with

A
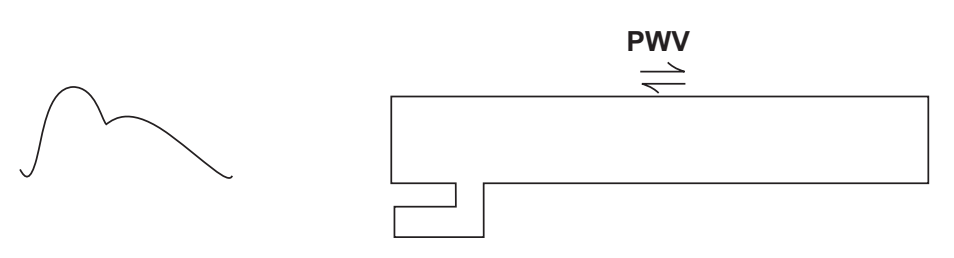

$P$
E
$R$
I
$P$
$H$
E
R
A
L

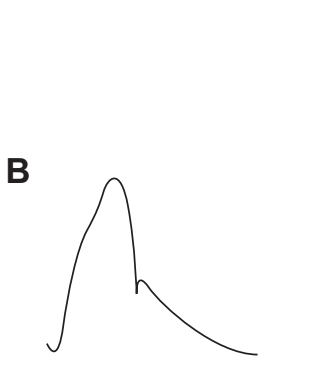

$\mathbf{H}$
$\mathbf{E}$
$\mathbf{A}$
$\mathbf{R}$
$\mathbf{T}$

Pressure wave at the ascending aorta

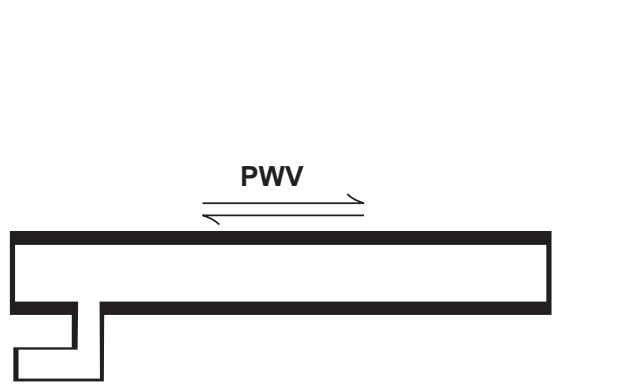

R
E
S
I
S
T
A
N
C
E

Figure 3 A classical and simple model for the definition of arterial stiffness and wave reflections. Top: a normal youthful arterial tree. Bottom: a stiffened arterial tree of an older person. The reflection of the pressure wave is represented by the diastolic wave in the first case (A) and by the late systolic wave in the second case (B). Coronary arteries are represented by hooks. PWV is an index of arterial stiffness and is dependent on degree of rigidity (thin line or thick line) of the arterial wall. ${ }^{1-4}$ Abbreviation: PWV, pulse wave velocity. 
systolic hypertension and end-stage renal disease, ACE inhibition restores the aortic pulse pressure amplification normally observed from central to peripheral arteries, causing a more substantial decrease in carotid than in brachial systolic and pulse pressure. ${ }^{6,7}$ Secondly, in subjects with essential hypertension, ACE inhibitors decrease brachial systolic BP more than $\beta$-blocking agents for the same decrease in brachial diastolic BP and mean arterial pressure. ${ }^{10}$

REASON (Preterax in Regression of Arterial Stiffness in a Controlled Double-blind Study) ${ }^{11}$ was the first clinical trial to investigate the long-term effects of antihypertensive drug treatment on central systolic BP and pulse pressure, aortic stiffness, and wave reflections. It was conducted in middleaged hypertensive subjects. Administration of perindopril, combined with a low dose of the diuretic indapamide, was compared with the effect of the $\beta$-blocking agent atenolol for one year. For the same diastolic BP and mean arterial pressure reduction, perindopril plus indapamide lowered systolic BP and pulse pressure more than atenolol (Figure 4). Moreover, the reduction was significantly more pronounced centrally (carotid artery) than peripherally (brachial artery, Figure 5). Although the two drug regimens lowered pulse wave velocity equally, only perindopril plus indapamide reduced central (carotid) pulse pressure and augmentation index. ${ }^{1-3,11,12}$ Central pulse pressure and augmentation index remained unchanged with atenolol. Furthermore, perindopril plus indapamide decreased cardiac hypertrophy more than atenolol. This effect was attributed to the augmentation index decline, indicating that the reduction of cardiac mass was related to central wave reflections. ${ }^{13-15}$ Furthermore, on drug treatment, the selective lowering of systolic BP (but not diastolic BP) with perindopril plus indapamide was significantly predicted by the baseline pulse wave velocity value. Thus, REASON emphasized the predictive values of pulse wave velocity, central systolic BP,

Table I The REASON study population $(\mathrm{n}=18 \mathrm{I})$ with central (carotid) and brachial measurements ${ }^{\prime \prime}$

\begin{tabular}{|c|c|c|c|c|}
\hline & Time & $\begin{array}{l}\text { Perindopril plus } \\
\text { indapamide }\end{array}$ & Atenolol & $P$ value \\
\hline \multirow[t]{3}{*}{ Brachial systolic BP $(\mathrm{mmHg})$} & Mo & $165.65 \pm 1.40$ & $162.18 \pm 1.36$ & 0.0786 \\
\hline & M6 & $142.39 \pm 1.39 *$ & $147.32 \pm 1.39 *$ & $0.014^{*}$ \\
\hline & MI2 & $137.80 \pm 1.34 *$ & $|42.88 \pm 1.4|^{*}$ & $0.0119 *$ \\
\hline \multirow[t]{3}{*}{ Carotid systolic BP (mmHg) } & Mo & $154.46 \pm 1.95$ & $152.37 \pm 1.90$ & 0.4431 \\
\hline & M6 & $133.34 \pm 1.62 *$ & $141.23 \pm 1.64 *$ & $0.0010^{*}$ \\
\hline & MI2 & $129.50 \pm 2.16^{*}$ & $144.99 \pm 2.20 *$ & $<0.000 I^{*}$ \\
\hline \multirow{3}{*}{$\begin{array}{l}\text { Brachial-carotid systolic BP ( } \mathrm{mmHg}) \\
\text { amplification }\end{array}$} & Mo & $9.40 \pm 1.54$ & $9.64 \pm 1.50$ & 0.9125 \\
\hline & M6 & $6.37 \pm 1.50 *$ & $2.43 \pm 1.54 *$ & $0.0709 *$ \\
\hline & MI2 & $8.28 \pm 1.53^{*}$ & $0.29 \pm 1.6 I^{*}$ & $0.0006 *$ \\
\hline \multirow[t]{3}{*}{ Aortic systolic BP (mmHg) } & Mo & $155.63 \pm 1.83$ & $151.23 \pm 1.80$ & 0.0891 \\
\hline & M6 & $135.22 \pm 1.78$ & $143.40 \pm 1.84$ & 0.0020 \\
\hline & MI2 & $128.32 \pm 1.97$ & $140.58 \pm 2.07$ & $<0.0001$ \\
\hline Brachial carotid or aortic diastolic & Mo & $97.09 \pm 0.77$ & $96.33 \pm 0.75$ & 0.4822 \\
\hline \multicolumn{5}{|l|}{$\mathrm{BP}(\mathrm{mmHg})$} \\
\hline & M6 & $85.10 \pm 0.79$ & $85.21 \pm 0.79$ & 0.9202 \\
\hline & MI2 & $83.93 \pm 0.74$ & $83.36 \pm 0.78$ & 0.6005 \\
\hline Brachial carotid or aortic & Mo & $119.94 \pm 0.75$ & $118.28 \pm 0.73$ & 0.1137 \\
\hline \multicolumn{5}{|l|}{$\mathrm{BP}(\mathrm{mmHg})$} \\
\hline & M6 & $104.19 \pm 0.87$ & $105.92 \pm 0.87$ & 0.1659 \\
\hline & MI2 & $101.83 \pm 0.83$ & $103.26 \pm 0.87$ & 0.2463 \\
\hline \multirow[t]{3}{*}{ Carotid augmentation index (\%) } & Mo & $29.09 \pm 2.24$ & $28.77 \pm 2.16$ & 0.9175 \\
\hline & M6 & $25.97 \pm 2.13$ & $27.74 \pm 2.14$ & 0.5608 \\
\hline & MI2 & $24.39 \pm 1.88^{*}$ & $29.73 \pm 1.93 *$ & $0.0527^{*}$ \\
\hline \multirow[t]{3}{*}{ Aortic augmentation index (\%) } & Mo & $30.06 \pm 0.98$ & $30.30 \pm 0.97$ & 0.8616 \\
\hline & M6 & $27.50 \pm 0.9 I^{*}$ & $30.97 \pm 0.95^{*}$ & $0.0101 *$ \\
\hline & MI2 & $26.28 \pm 0.94^{*}$ & $30.18 \pm 1.00 *$ & $0.0057^{*}$ \\
\hline \multirow[t]{3}{*}{ Pulse wave velocity (m/sec) } & Mo & $12.9 \mid \pm 0.26$ & $12.46 \pm 0.25$ & 0.2161 \\
\hline & M6 & $11.90 \pm 0.21$ & $12.02 \pm 0.21$ & 0.7008 \\
\hline & $M 12$ & $11.77 \pm 0.23$ & $11.90 \pm 0.24$ & 0.6945 \\
\hline
\end{tabular}

Note: *Significant intergroup comparisons. Main cardiovascular parameters: adjusted absolute means \pm standard error of means are presented at M0, M6, and MI2. Abbreviations: BP, blood pressure; M, month; REASON, Preterax in Regression of Arterial Stiffness in a Controlled Double-blind Study. 
and pulse pressure in the mechanisms of BP reduction in hypertensive subjects. ${ }^{16} \mathrm{~A}$ confirmation of all these findings was obtained later from ASCOT (the Anglo-Scandinavian Cardiac Outcomes Trial) in which the role of central BP as predictive of cardiovascular events was further confirmed. ${ }^{17}$

\section{Transduction within the arterial wall, pulse pressure, and angiotensin II blockade}

Mechanical forces involve pulsatile and steady pressure components but also have to integrate some biologic components, including those relating to structural and biochemical factors acting on arterial vessels. Focal adhesion formations of extracellular matrix and integrin-specific signaling in vascular smooth muscle cells are essential for mechanotransduction of angiotensin blockade within the arterial wall.

Dense plaques, which are composed of cytoskeletal proteins linked to the extracellular matrix by integrin receptors, are major sites of anchorage between vascular smooth muscle and the extracellular matrix. They represent key
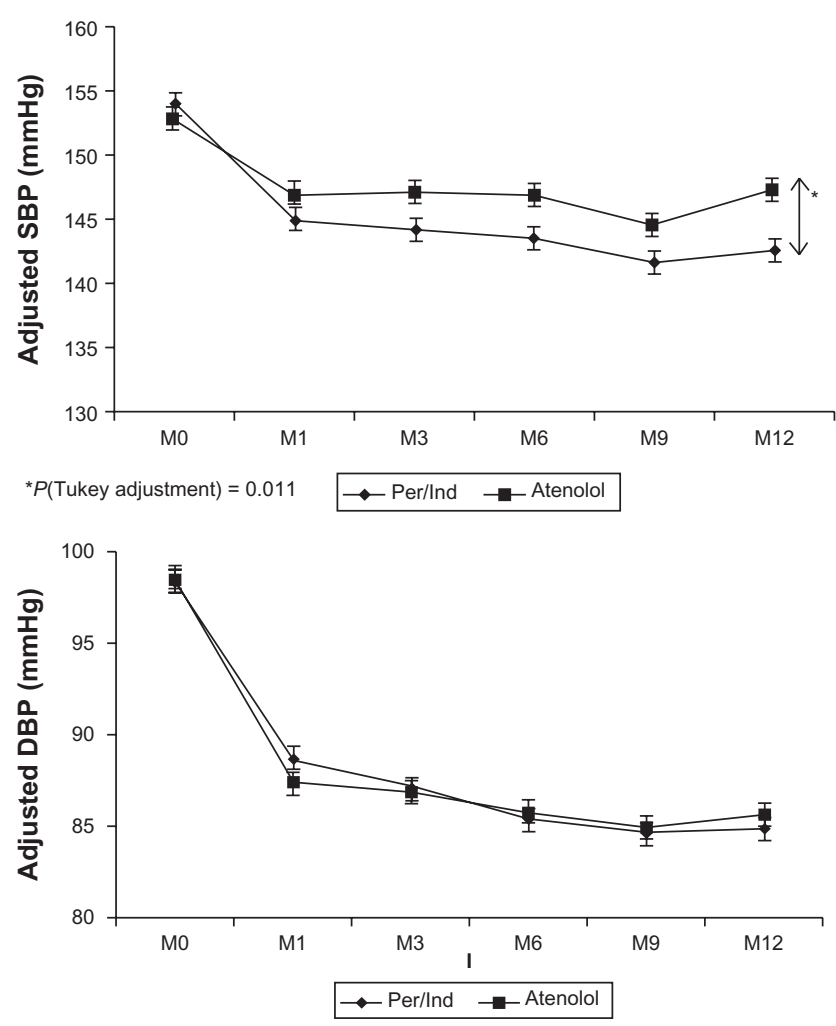

Figure 4 Overall intention-to-treat population in REASON: adjusted values $( \pm S D)$ in brachial SBP and DBP, measured each month in the perindopril plus indapamide and atenolol groups. There was no difference between groups for DBP but only for SBP and exclusively at month 12 .

Abbreviations: DBP, diastolic blood pressure; Per-Ind, perindopril plus indapamide; SBP, systolic blood pressure; M, month; SD, standard deviation; REASON, Preterax in Regression of Arterial Stiffness in a Controlled Double-blind Study.

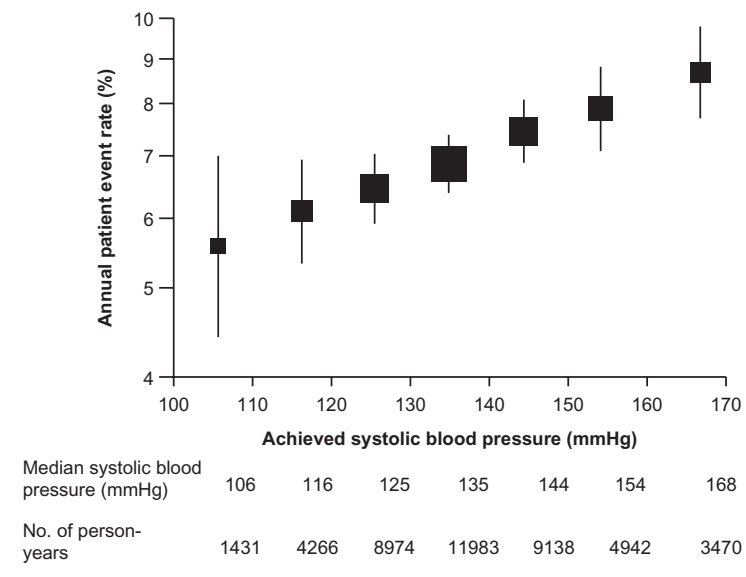

Figure 5 Incidence of all renal events in $\mathrm{ADVANCE}^{31}$ according to achieved blood pressure levels, adjusted for age, gender, duration of diabetes, glycosylated hemoglobin, currently treated hypertension, history of macrovascular disease, electrocardiogram abnormalities (ventricular hypertrophy, $Q$ waves, or atrial fibrillation), triglycerides, low-density lipoprotein cholesterol, high-density lipoprotein cholesterol, body mass index, current smoking, current alcohol use, and study drug. Solid boxes represent estimates of event rates, centers of which are placed at the intersection of the point estimate and median systolic blood pressure value. Areas of the boxes are proportional to the number of events, and vertical bars represent $95 \%$ confidence interval. The rate of all renal events was significantly associated with achieved systolic blood pressure levels $(P<0.000 \mathrm{I})$.

Abbreviation: ADVANCE, Action in Diabetes and Vascular Disease: Preterax and Diamicron MR Controlled Evaluation study.

elements for interaction between mechanical forces and elastic materials. Integrins exist as $\alpha \beta$ pairings. They interact with extracellular matrix components, including fibronectin (ligand for $\alpha 5 \beta 1$ and $\alpha v \beta 3$ ), vitronectin (ligand for $\alpha v \beta 3$ ), and laminin (ligand for $\alpha 6 \beta 1$ ). ${ }^{18}$ Interactions of specific extracellular matrix proteins with their integrin receptors play a central role in transmitting mechanical forces to vascular smooth muscle. ${ }^{19,20}$ Many of these integrins are capable of forming complexes with fibronectin, a glycoprotein that plays an important role in the organization and assembly of the extracellular matrix.

When cyclic mechanical strain is applied to matrixes containing different adhesion proteins, fibronectin produces one of the largest mitogenic responses in rat vascular smooth muscle. ${ }^{20}$ In addition, expression of fibronectin and its $\alpha 5 \beta 1$ receptor are increased in the spontaneously hypertensive rat aorta. The increase of fibronectin may reflect an increased number of mechanical attachments between the extracellular matrix and collagen fibers within the media. From a mechanical point of view, an increased number of cell matrix attachments promote increased stiffness and mechanical strength.

These changes have been studied in situations involving normal or increased sodium intake in the presence of angiotensin II and/or aldosterone stimulation and blockade..$^{21-26}$ With a normal sodium diet, angiotensin or aldosterone blockade reduces mean arterial pressure and pulse pressure, and decreases collagen 
accumulation, fibronectin, and its integrin receptor. On a high sodium diet, mean arterial pressure, but not central pulse pressure, is reduced in association with collagen accumulation, increased fibronectin, and increased arterial stiffness.

It is worth noting that the mechanical contribution of mean arterial pressure and pulse pressure may vary markedly according to age or the vascular territory involved. ${ }^{27}$ Thus, pulse pressure mechanotransduction may predominate in the heart rather than in the brain or kidney because only the former territory involves active periodic autocontractions. Furthermore, with increasing age, reflection coefficients are located much closer to target organs (ie, the heart, brain, or kidney). This finding suggests that pulsatility and wave reflections may be transmitted to these organs in the presence of a defect in myogenic tone. This defect is commonly observed in subjects with type 2 diabetes mellitus, those with uninephrectomy or obesity, and often in older patients with systolic hypertension. ${ }^{28-31}$ Finally, many factors linked to mechanical stress, particularly pulsatility and wave reflections, may affect each particular organ locally, thereby modulating or interacting with a local hormonal system. A typical example would be subjects with hypertension and type 2 diabetes mellitus in whom perindopril reduces both systolic BP and renal events.

In conclusion, the renin-angiotensin-aldosterone system has been considered for many years only as a hormonal factor of the basis of hypertension and its treatment. With the development of antihypertensive therapy, the same system has come to be understood as a modulating antioxidative and anti-inflammatory factor contributing to the reduction of cardiovascular morbidity and mortality through its antifibrotic effects, mainly observed in the elderly and particularly in the large arterial system. This system remains under investigation in older populations.

\section{Acknowledgments}

This work was performed with the help of INSERM (Institut de la Santé et de la Recherche Médicale) and GPH Cardiovascular (Groupe de Pharmacologie et d'Hémodynamique Cardio-vasculaire), Paris. Thanks are extended to Dr Anne Safar for helpful and stimulating discussions.

\section{Disclosure}

The author reports no conflict of interest in this work.

\section{References}

1. Nichols WW, O'Rourke MF. McDonald's Blood Flow in Arteries: Theoretical, Experimental and Clinical Principles. 4th ed. London: Edward Arnold: 2006.
2. Safar ME, Levy BI, Struijker-Boudier H. Current perspectives on arterial stiffness and pulse pressure in hypertension and cardiovascular diseases. Circulation. 2003;107(22):2864-2869.

3. Staessen JE, Li Y, Thijs L, Wang JG. Arterial stiffness in hypertension. In: Safar ME, O'Rourke MF, editors. Handbook of Hypertension. Edinburgh: Elsevier; 2006.

4. Westerhof N, Sipkema P, van der Bos GC, Etzinga G. Forward and backward waves in the arterial system. Cardiovasc Res. 1972;6(6):648-656.

5. Chen CH, Ting CT, Lin SJ, et al. Different effects of fosinopril and atenolol on wave reflections in hypertensive patients. Hypertension. 1995;25(5):1034-1041.

6. London GM, Pannier B, Guerin AP, Marchais SJ, Safar ME, Cuche JL. Cardiac hypertrophy, aortic compliance, peripheral resistance, and wave reflection in end-stage renal disease. Comparative effects of ACE inhibition and calcium channel blockade. Circulation. 1994;90(6): 2786-2796.

7. Ting CT, Yang TM, Chen JW, Chang MS, Yin FC. Arterial hemodynamics in human hypertension. Effects of angiotensin converting enzyme inhibition. Hypertension. 1993;22(6):839-846.

8. Simon AC, Levenson JA, Bouthier JL, Safar ME. Captopril-induced changes in large arteries in essential hypertension. Am J Med. 1984; 76(5B):71-75.

9. Topouchian J, Asmar R, Sayegh F, et al. Changes in arterial structure and function under trandolapril-verapamil combination in hypertension. Stroke. 1999;30;(5):1056-1064.

10. Ting CT, Chen CH, Chang MS, Yin FC. Short- and long-term effects of antihypertensive drugs on arterial reflections, compliance, and impedance. Hypertension. 1995;26(3):524-530.

11. London GM, Asmar RG, O'Rourke MF, Safar ME; on behalf of the REASON project. Mechanism(s) of selective systolic blood pressure reduction after a low-dose combination of perindopril/indapamide in hypertensive subjects: Comparison with atenolol. $\mathrm{J} \mathrm{Am} \mathrm{Coll} \mathrm{Cardiol}$. 2004;43(1):92-99.

12. Westerhof BE, Stergiopulos N, Noble MIM. Snapshots of hemodynamics: An Aid for Clinical Research and Graduate Education. London: Springer; 2004.

13. Hayoz D, Rutschmann B, Perret F, et al. Conduit artery compliance and distensibility are not necessarily reduced in hypertension. Hypertension. 1992;20(1):1-6.

14. Kool MJ, van Merode T, Reneman RS, Hoeks AP, Struyker Boudier HA, van Bortel LM. Evaluation of reproducibility of a vessel wall movement detector system for assessment of large artery properties. Cardiovasc Res. 1994;28(5):610-614.

15. De Luca N, Asmar RG, London GM, O'Rourke MF, Safar ME. Selective reduction of cardiac mass and central blood pressure on low-dose combination perindopril/indapamide in hypertensive subjects. J Hypertens. 2004;22(8):1623-1630.

16. Protogerou A, Blacher J, Stergiou GS, Achimastos A, Safar ME. Blood pressure response under chronic antihypertensive drug therapy: The role of aortic stiffness in the REASON (Preterax in Regression of Arterial Stiffness in a Controlled Double-blind) study. $J$ Am Coll Cardiol. 2009;53(5):445-451.

17. Williams B, Lacy PS, Thom SM, et al; CAFE Investigators; AngloScandinavian Cardiac Outcomes Trial. Differential impact of blood pressure-lowering drugs on central aortic pressure and clinical outcomes: Principal results of the Conduit Artery Function Evaluation (CAFE) study. Investigators; CAFE Steering Committee and Writing Committee. Circulation. 2006;113(9):1213-1225.

18. Moiseeva EP. Adhesion receptors of vascular smooth muscle cells and their functions. Cardiovasc Res. 2001;52(3):372-386.

19. Ingber D. Integrins as mechanochemical transducers. Curr Opin Cell Biol. 1991;3(5):841-848.

20. Wilson E, Sudhir K, Ives HE. Mechanical strain of rat vascular smooth muscle cells is sensed by specific extracellular matrix/integrin interactions. J Clin Invest. 1995;96(5):2364-2372. 
21. Intengan HD, Schiffrin EL. Structure and mechanical properties of resistance arteries in hypertension: Role of adhesion molecules and extracellular matrix determinants. Hypertension. 2000;36(3):312-318.

22. Koffi I, Lacolley P, Kirchengaast M, Pomies JP, Laurent S, Benetos A. Prevention of arterial structural alterations with verapamil and trandolapril and consequences for mechanical properties in spontaneously hypertensive rats. Eur J Pharmacol. 1998;361(1):51-60.

23. Labat C, Lacolley P, Lajemi M, de Gasparo M, Safar ME, Benetos A. Effects of valsartan on mechanical properties of the carotid artery in spontaneously hypertensive rats under high-salt diet. Hypertension. 2001;38(3):439-443.

24. Lacolley P, Labat C, Pujol A, Delcayre C, Benetos A, Safar M. Increased carotid wall elastic modulus and fibronectin in aldosterone-salt-treated rats: Effects of eplerenone. Circulation. 2002;106(22):2848-2853.

25. Louis H, Kakou A, Regnault V, et al. Role of alpha1beta1-integrin in arterial stiffness and angiotensin-induced arterial wall hypertrophy in mice. Am J Physiol Heart Circ Physiol. 2007;293(4):H2597-H2604.

26. Sartore S, Scatena M, Chiavegato A, Faggin E, Giuriato L, Pauletto P Myosin isoform expression in smooth muscle cells during physiological and pathological vascular remodeling. J Vasc Res. 1994;31(2):61-81.

27. Lehoux S, Tedgui A. Cellular mechanics and gene expression in blood vessels. J Biomech. 2003;36(5):631-643.

28. Fesler P, Safar ME, du Cailar G, Ribstein J, Mimran A. Pulse pressure is an independent determinant of renal function decline during treatment of essential hypertension. J Hypertens. 2007;25(9):1915-1920.

29. Matrougui K, Schiavi P, Guez D, Henrion D. High sodium intake decreases pressure-induced (myogenic) tone and flow-induced dilation in resistance arteries from hypertensive rats. Hypertension. 1998;32(1): 176-179.

30. Verhave JC, Fesler P, du Cailar G, Ribstein J, Safar ME, Mimran A. Elevated pulse pressure is associated with low renal function in elderly patients with isolated systolic hypertension. Hypertension. 2005;45(4): 586-591.
31. Patel A, MacMahon S, Chalmers J, et al. Effects of a fixed combination of perindopril and indapamide on macrovascular and microvascular outcomes in patients with type 2 diabetes mellitus (the ADVANCE trial): A randomised controlled trial. Lancet. 2007;370(9590):829-840.

32. Asmar RG, London GM, O’Rourke MF, Safar ME; REASON Project Coordinators and Investigators. Improvement in blood pressure, arterial stiffness and wave reflections with a very-low-dose perindopril/ indapamide combination in hypertensive patients: A comparison with atenolol. Hypertension. 2001;38(4):922-926.

33. Morgan T, Lauri J, Bertram D, Anderson A. Effect of different antihypertensive drug classes on central aortic pressure. Am J Hypertens. 2004;17(2):118-123.

34. Deary AJ, Schumann AL, Murfet H, Haydock S, Foo RS, Brown MJ. Influence of drugs and gender on the arterial pulse wave and natriuretic peptide secretion in untreated patients with essential hypertension. Clin Sci. 2002;103(5):493-499.

35. Neal DA, Brown MJ, Wilkinson IB, Byrne CD, Alexander GJ. Hemodynamic effects of amlodipine, bisoprolol, and lisinopril in hypertensive patients after liver transplantation. Transplantation. 2004; 77(5):748-750.

36. Hirata K, Vlachopoulos C, Adji A, O’Rourke MF. Benefits from angiotensin-converting enzyme inhibitor 'beyond blood pressure lowering': Beyond blood pressure or beyond the brachial artery? J Hypertens. 2005;23(3):551-556.

37. Dhakam Z, McEniery CM, Yasmin, Cockcroft JR, Brown MJ, Wilkinson IB. Atenolol and eprosartan: Differential effects on central blood pressure and aortic pulse wave velocity. Am J Hypertens. 2006;19(2): 214-219.

38. Dart AM, Cameron JD, Gatzka CD, et al. Similar effects of treatment on central and brachial blood pressures in older hypertensive subjects in the Second Australian National Blood Pressure Trial. Hypertension. 2007;49(6):1242-1247. 


\section{Appendix}

Table I Differences between central and brachial systolic pressure changes related to angiotensin blockade ${ }^{17,32-38}$

\begin{tabular}{|c|c|c|c|c|}
\hline Reference & $\mathbf{n}$ & Drug & $\begin{array}{l}\text { Difference between } \\
\text { central and peripheral } \\
\text { systolic pressure change }\end{array}$ & $\begin{array}{l}\text { Net difference between ACE } \\
\text { inhibitor/sartan and other } \\
\text { antihypertensive agents }\end{array}$ \\
\hline \multirow[t]{2}{*}{ Asmar et $\mathrm{al}^{32}$} & 184 & Perindopril & $-06 \mathrm{mmHg}$ & $7.6 \mathrm{mmHg}$ \\
\hline & 170 & plus indapamide Atenolol & $-8.2 \mathrm{mmHg}$ & \\
\hline Williams et al ${ }^{17}$ & 1042 & Amlodipine-perindopril & $12.0 \mathrm{mmHg}$ & \\
\hline Morgan et $\mathrm{al}^{133}$ & 32 & $\begin{array}{l}\text { Perindopril } \\
\text { or enalapril }\end{array}$ & $4.7 \mathrm{mmHg}$ & \\
\hline Deary et $\mathrm{al}^{34}$ & 30 & Lisinopril & I mmHg & \\
\hline Neal et a ${ }^{35}$ & 13 & Lisinopril & $10 \mathrm{mmHg}$ & \\
\hline Hirata et $\mathrm{al}^{36}$ & 30 & Ramipril & $-2.0 \mathrm{mmHg}$ & \\
\hline Dhakam et $\mathrm{al}^{37}$ & 21 & Eprosartan & $0 \mathrm{mmHg}$ & \\
\hline Dart et $\mathrm{al}^{38}$ & 258 & ACE inhibitor & $\mathrm{I} \mathrm{mmHg}$ & \\
\hline
\end{tabular}

Abbreviation: ACE, angiotensin-converting enzyme.

\section{Publish your work in this journal}

The International Journal of Nephrology and Renovascular Disease is an international, peer-reviewed open-access journal focusing on the pathophysiology of the kidney and vascular supply. Epidemiology, screening, diagnosis, and treatment interventions are covered as well as basic science, biochemical and immunological studies. The journal welcomes original research, clinical studies, reviews \& evaluations, expert opinion and commentary, case reports and extended reports. The manuscript management system is completely online and includes a very quick and fair peer-review system, which is all easy to use. Visit http://www.dovepress.com/ testimonials.php to read real quotes from published authors.

Submit your manuscript here: http://www.dovepress.com/international-journal-of-nephrology-and-renovascular-disease-journal 